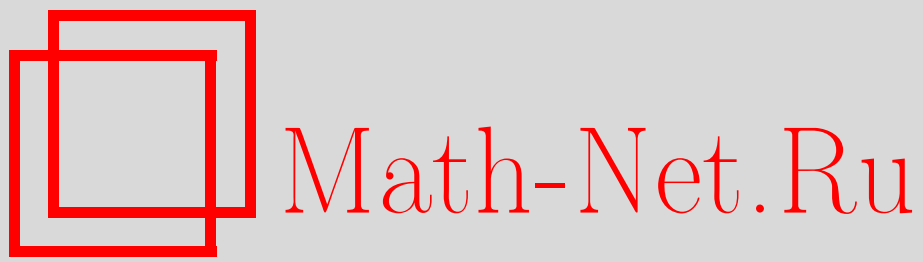

А. Варламов, Об оvо, Квант, 2020, номер 6, 9-13

DOI: https://doi.org/10.4213/kvant20200602

Использование Общероссийского математического портала Math-Net.Ru подразумевает, что вы прочитали и согласны с пользовательским соглашением http: //www . mathnet.ru/rus/agreement

Параметры загрузки:

IP : 54.80 .97 .219

26 апреля 2023 г., $17: 43: 17$

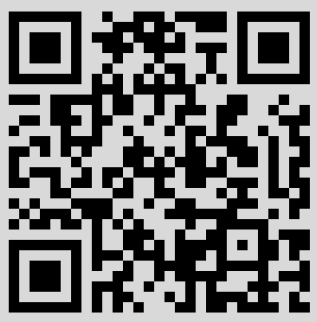




\section{Oб ovo}

\section{А.ВАРЛАМОВ}

Главное в том, что, как бы осторожно мы ни старались вбить яйцо в чашку, мы не можем изменить законов физики. Яйцо может не растечься, а у умелого кулинара никогда не растечется, но оно неизбежно будет падать по вертикали с ускорением силы тяжести.

В.Похлебкин. Тайны хорошей кухни

$\mathrm{B}$ ПЕРЕВОДЕ С ЛАТЫНИ «АВ ОVО» буквально означает «от яйца». В переносном же смысле это выражение употребляют, когда хотят указать на изначальность, первичность чего-либо. Именно этот переносный смысл и вкладывали древние как основной в слова «ab ovo». Сами того не ведая, они тем самым разрешили в пользу яйца существующий с незапамятных времен софизм: что появилось раньше - курица или яйцо? Мы этот вопрос оставим в стороне, а займемся некоторыми физическими явлениями, избрав в качестве предмета исследования... куриное яйцо.

Кто не помнит роковой причины раздора между Лилипутией и империей Блефуску, описанного в «Путешествиях Гулливера»? Ею стал указ императора Лилипутии, предписывающий всем подданным под страхом смертной казни разбивать яйца с острого конца. Гулливер полагал, что выбор конца, с которого следует разбивать яйцо, дело хозяйское. С какого хочешь - с такого и разбивай. Мы полностью согласны с такой позицией, но все-таки зададимся вопросом: с какого конца яйцо легче разбить? Решение этой задачи поможет, например, выбрать правильную тактику при «сражениях на вареных яйцах», которые раньше часто возникали среди детей за пасхальным столом.

Как правильно поступать: нападать на противника или ждать нападения самому;

DOI: https://doi.org/10.4213/kvant20200602 выбрать большое яйцо или маленькое; держать его острым или тупым концом к противнику? Вот основные вопросы тактики и стратегии в таком сражении. Бытует мнение, что выигрывает нападающий. Однако при равномерном движении яйца безразлично нападать самому или ждать нападения противника. Чтобы убедиться в этом, не надо бить яйца: достаточно вспомнить принцип относительности Галилея и «перейти» в систему отсчета, в которой нападающий покоится. В ней он из «агрессора» автоматически превращается в «пострадавшую сторону» .

Рассмотрим теперь сам процесс столкновения двух яиц. Мы будем считать, что яйца совершенно одинаковые и по размерам и по форме и что скорлупа у них «рассчитана» на одну и ту же предельную нагрузку. Сталкиваются яйца вдоль оси вращения, одно острым концом, другое тупым (рис.1). Предположим, что область

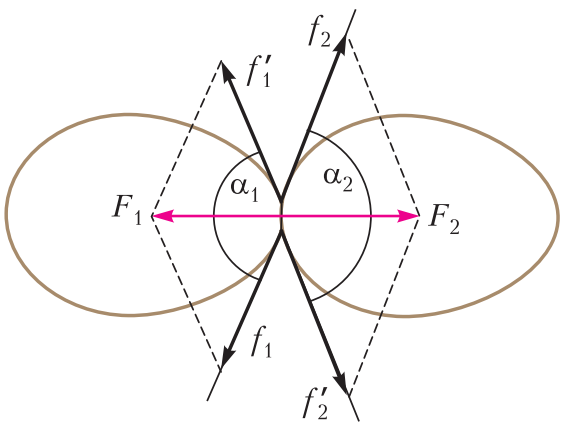

Рис. 1. Упругая фаза соударения двух яиц соприкосновения яиц - это небольшой круг радиусом $r$. Не важно, будет ли граница плоской или выгнутой в какуюлибо сторону. Существенно, что согласно третьему закону Ньютона силы, действующие в процессе столкновения со стороны одного яйца на другое, равны по абсолютной величине и направлены в противоположные стороны. При передаче этой силы 
от области соприкосновения всему яйцу задействованы в первую очередь силы упругости скорлупы (вклад жидких белка и желтка здесь можно предположить независящим от формы конца яйца, участвующего в соударении). Можно считать, что они направлены по касательным вдоль скорлупы. На левое яйцо со стороны правого действуют силы $\vec{f}_{1}$ и $\vec{f}_{1}^{\prime}$, дающие в сумме силу $\vec{F}_{1}$, действующую на скорлупу (кроме зоны контакта) и ее содержимое. Противоположные силы упругости $-\vec{f}_{1}$ и $-\vec{f}_{1}^{\prime}$ в сумме дают силу, компенсирующую силу воздействия правого яйца на зону контакта. Аналогично, для правого яйца мы нарисуем ту же картину с силами $\vec{f}_{2}, \vec{f}_{2}^{\prime}$ и их суммой $\vec{F}_{2}$. Третий закон Ньютона даст нам соотношение

$$
F_{1}=F_{2} \text {, или } 2 f_{1} \cos \frac{\alpha_{1}}{2}=2 f_{2} \cos \frac{\alpha_{2}}{2} .
$$

Но углы $\alpha_{1}$ и $\alpha_{2}$ будут различаться, так как при той же величине $r$ будут отличаться радиусы кривизны широкого и узкого концов яйца. Ясно, что $\alpha_{1}<\alpha_{2}$, и мы получим $f_{1}<f_{2}$. Так что, как видно, действительно выгоднее сражаться, держа яйцо острым концом к противнику. А в настоящем бою острая шпага или стилет может проткнуть доспехи или щит. Щит же никогда не проткнет шпагу, максимум сломает ее.

Имеется и еще один довод в пользу такой стратегии: внутри яйца у тупого конца расположен «воздушный мешок», и из-за этого тупой конец оказывается дополнительно ослабленным (попробуйте объяснить этот факт).

Обратим внимание читателя на то, что приведенный анализ сил указывает путь к победе с помощью маленькой хитрости. Не нарушая принципа относительности Галилея, нападающий имеет дополнительный шанс на победу, даже если его противник опытен и сражается острым концом: воспользовавшись своей активной позицией, нападающий может ударить противника не в острие, а чуть сбоку, где кривизна меньше, и яйцо расколется легче.

...В магазинах иногда можно встретить забавную игрушку «волчок» - изготовленный из дерева или пластмассы усеченный

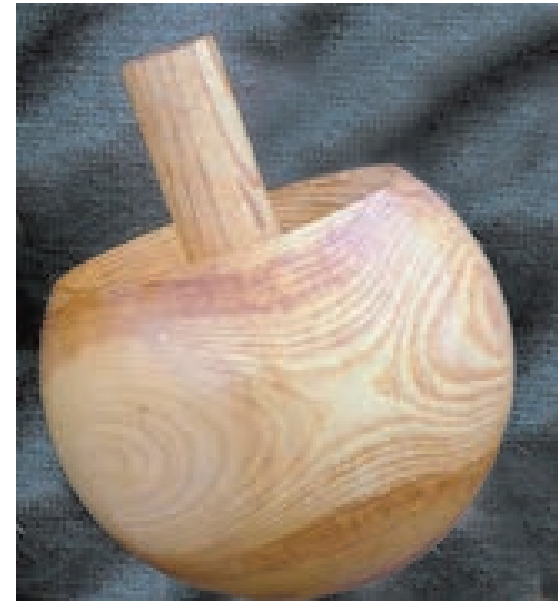

Рис. 2. Волчок Томсона

шарик с хвостиком (рис. 2). Раскрутив его за этот хвостик, можно наблюдать необычное явление: в некоторый момент волчок переворачивается и становится «вверх ногами» - на свой хвостик. Очевидно, что потенциальная энергия волчка в поле тяжести при этом возрастает! Объяснение такому странному поведению много лет назад дал известный английский физик Уильям Томсон, с тех пор такой волчок называется волчком Томсона.

Оказывается, вареное яйцо может вести себя так же, как волчок Томсона. Возьмем гладкую кафельную плитку и быстро раскрутим на ней сваренное вкрутую яйцо. После двух-трех оборотов яйцо встанет на свой острый конец и будет вращаться вокруг своей продольной оси! И только лишь после значительного замедления вращения яйцо, под влиянием сил тяжести и трения, начнет все больше и больше раскачиваться из стороны в сторону, пока его боковая сторона не коснется подставки. Этот опыт удается только в том случае, если яйцо хорошо «проварено», сырое яйцо так вращаться не будет. Дело в том, что вязкое трение между слоями жидкости в яйце и между белком и скорлупой существенно тормозит вращение, поэтому раскрутить сырое яйцо до нужной угловой скорости не удается. Благодаря такому различию в поведении вареного и сырого яиц их всегда можно различить не разбивая. Для этого испытуемое яйцо достаточ- 
но раскрутить на столе. Сырое яйцо, совершив несколько оборотов, остановится, а вареное будет еще долго вращаться.

...В предыдущих опытах нам понадобилось вареное яйцо. А что с ним происходит в процессе термической обработки? И как правильно его сварить, чтобы оно не треснуло и не взорвалось, не стало «крутым», а получилось «всмятку»? Почему опытная хозяйка варит яйцо в соленой воде? На эти и другие кулинарные вопросы нелегко найти ответы даже в толстой поваренной книге.

По своей сути, процесс варки яйца, как и многие другие способы тепловой обработки пищи (например, жарка, запекание и т.д.), основан на процессе денатурации протеинов (белков). При высокой температуре эти сложные органические молекулы изменяют свою форму и пространственную структуру. Денатурация может быть вызвана многими факторами, включая воздействие химических веществ, ферментов и т.д. В отличие от физики неорганической материи, где при фиксированном давлении известно точное значение температуры фазовых переходов (например, плавления или кипения), со столь сложными органическими соединениями, как белки, все не так просто. Тем не менее о состоянии белка можно судить, например, изучая степень его прозрачности. Выбирая скорость потока тепла, более или менее соответствующую условиям варки яйца, можно определить, что максимальная температура денатурации его белка приблизительно равна $68^{\circ} \mathrm{C}$. Что же касается желтка, то его денатурация происходит при более низких температурах $63-65{ }^{\circ} \mathrm{C}$. Более точно говорить о температуре такого перехода не имеет смысла, так как денатурация протеинов происходит не резко, а постепенно. Кроме того, эта величина зависит от таких факторов, как содержание соли, возраста яйца и т.д.

Так как же объяснить возможность приготовления яйца всмятку, с относительно твердым белком и жидким желтком, которые многие едят на завтрак? Почему менее температурно-устойчивый желток в приготовленном всмятку яйце остается жид- ким, в то время как денатурирующий при несколько более высокой температуре белок затвердевает?

С физической точки зрения, при попадании холодного яйца в кипящую воду от его поверхности к центру начинает свое движение температурный фронт. Проблема распространения тепла в среде хорошо изучена математической физикой. Мы же ограничимся утверждением, что температурный фронт проникает внутрь яйца в зависимости от времени по так называемому корневому закону

$$
L(t)=\sqrt{\frac{\pi \kappa}{c \rho} t},
$$

где $L(t)$ - расстояние от поверхности, на котором за прошедшее время $t$ температура уже приблизилась к температуре окружающей кипящей воды, $к=0,56$ Вт/ $(м \cdot K)-$ теплопроводность, $c=3,14 \cdot 10^{3}$ Дж $($ кг $\cdot$ K $)-$ удельная теплоемкость, $\rho=1040$ кг $/ \mathrm{m}^{3}-$ плотность белка. Подставляя приведенные численные значения, находим, что за время варки яйца, скажем, 5 минут температура поднимется до величины, сравнимой со $100{ }^{\circ} \mathrm{C}$, в слое порядка 1,25 см от скорлупы. Это и объясняет денатурацию находящегося около нее белка. А до центра яйца высокая температура дойти не успевает, вот желток и остается жидким.

Отметим, что незначительное, на первый взгляд, различие в температурах денатурации белка и желтка позволяет японцам готовить необычное для европейцев блюдо под названием «Онсэн Тамаго». Это куриное яйцо, варенное при температуре $65^{\circ} \mathrm{C}$ на протяжении длительного времени (около часа). В результате возникает блюдо, прямо противоположное яйцу всмятку: желток в нем оказывается твердым, а яичный белок остается жидким, хотя и помутневшим. Такой разительный контраст в конечной форме одного и того же продукта при, казалось бы, одном и том же виде температурной обработки обусловлен различием в температурных режимах приготовления: если яйцо всмятку готовится при высокой температуре за короткое время, то «Онсэн Тамаго» готовится при 
температуре относительно низкой и долго. Любопытно, что рецепт «Онсэн Тамаго» используется на термальных курортах Японии. Посетители, прежде чем отправится в термы, кладут сырые яйца в специальный бассейн с температурой $65^{\circ} \mathrm{C}$, а по возвращению вынимают готовое блюдо.

Расчет времени варки яйца всмятку в приближении яйца эллипсоидом был проделан английским физиком Питером Берхэмом. В своей книге «Наука кулинарии» он приводит формулу, связывающую время варения яйца $t$ (мин) в воде температуры $T_{\text {к }}$ с его малым диаметром $d$ (см) (рис.3), начальной температурой яйца $T_{0}$ и желаемой конечной температурой желтка $T_{\phi}$ :

$$
t=0,15 d^{2} \ln \left(2 \frac{T_{\mathrm{K}}-T_{0}}{T_{\mathrm{K}}-T_{\phi}}\right) .
$$

Для нормального яйца с $d=4 \mathrm{~cm}$, только что взятого из холодильника $\left(T_{0}=5^{\circ} \mathrm{C}\right)$ и помещенного в кипящую при нормальных условиях воду $\left(T_{\kappa}=100^{\circ} \mathrm{C}\right)$, которое мы хотим сварить «всмятку» $\left(T_{\phi}=63^{\circ} \mathrm{C}\right)$, время варки составит $t_{1}=3$ мин $54 \mathrm{c}$. Для крупного же яйца с $d=6$ см это время более чем удваивается: $t_{2}=8$ мин $48 \mathrm{c}$.

Из формулы Берхэма видна также и необходимость пересмотра времен приготовления блюд высоко в горах. Действительно, температура кипения воды существенно меняется, а именно уменьшается, с высотой над уровнем моря, так что времена варки продуктов удлиняются по

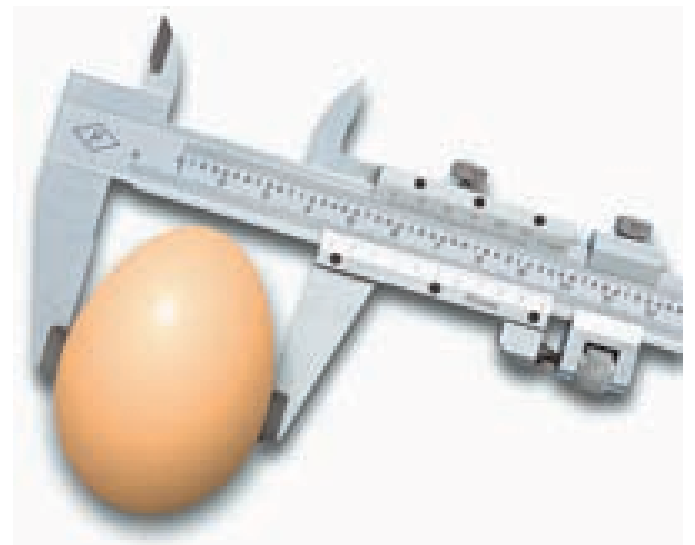

Рис. 3. Измерение малого диаметра яйца сравнению с соответствующими величинами, установленными на уровне моря и внесенными в кулинарные наставления. Так, приготовление яйца всмятку на высоте 5000 м, где вода кипит при $80^{\circ} \mathrm{C}$, уже займет не 4 минуты, а 5,5 минут.

При варке яйца в пресной воде оно лежит на дне (его плотность больше плотности воды). При кипении у дна кастрюли возникают вихревые потоки воды, которые увлекают яйцо и могут привести к раскалыванию скорлупы при ударах о стенки или дно. При этом белок выливается через образовавшуюся трещину в окружающую воду и затвердевает хлопьями. Блюдо испорчено! Однако достаточно немного подсолить воду - и такого, как правило, не случается. В свете вышесказанного понятно, что соль способствует более быстрому сворачиванию и трещина просто «зарастает» свернувшимся белком.

...Итак, яйцо сварилось. Выньте его ложкой из кипятка и быстро, пока яйцо еще влажное, возьмите в руки. Хотя яйцо горячее, удержать его в руках можно. Однако по мере его высыхания это делать становится все труднее и труднее. Вскоре яйцо станет сухим, и тогда его в руках уже не удержать - очень горячо! С чем связано это явление?

Ответив на предыдущий вопрос, попытайтесь яйцо очистить. Вы увидите, что скорлупа накрепко прилипла и вырывается только с кусками белка. Этого можно было бы избежать, если бы вы сразу опустили сваренное яйцо в холодную воду: у белка и скорлупы различные коэффициенты объемного расширения, и при резком охлаждении белок сжимается сильнее, чем скорлупа, и сам от нее «отлипает». Яйцо легко чистится.

...Пока мы видели, как проявляются в свойствах яйца законы механики, гидродинамики и молекулярной физики. А какие электрические явления можно наблюдать с его помощью?

Одно из них - взрыв яйца в микроволновой печке благодаря быстрому разогреву его внутренности при протекании индукционных токов. Есть и другие, более безо- 
бидные электрические свойства. Яйцо диэлектрик. Именно это свойство яичной скорлупы и использовал Майкл Фарадей для демонстрации явления электризации.

Возьмите сырое яйцо и проделайте иглой в нем две дырочки - одну побольше, другую поменьше. Дуя в меньшую из них, вы можете выдуть все содержимое яйца и у вас в руках останется пустая целая скорлупа. Поднесите теперь к ней наэлектризованную эбонитовую палочку или обыкновенную пластмассовую расческу, которой вы только что причесались. Теперь, куда бы вы ни перемещали палочку или расческу, скорлупа, как собачонка на привязи, неотступно будет следовать за ними .

С помощью пустой яичной скорлупы можно сконструировать модель реактивного автомобиля. Для этого достаточно заклеить большую дырку жевательной резинкой, заполнить скорлупу водой и установить ее на легчайшей тележке со свободно вращающимися колесиками (рис.4). Под яйцом следует положить ку-

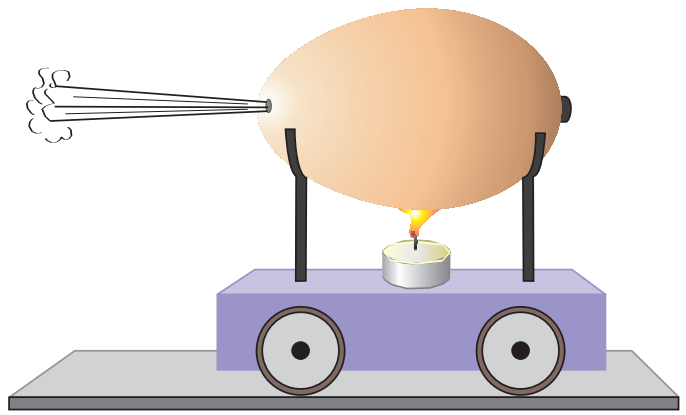

Рис. 4. Реактивный движитель

сочек сухого спирта и поджечь его. Вода вскоре закипит, и вырывающиеся из малого отверстия пары, благодаря принципу реактивного движения, начнут разгонять тележку.

...Мы уже рассказали, как отличить, не разбивая, вареное яйцо от сырого. А можно ли, не разбивая яйцо, узнать - свежее оно или нет? Оказывается, можно. Для этого достаточно опустить сырое яйцо в стакан с водой (рис.5). Свежее яйцо, которое было снесено всего несколько дней

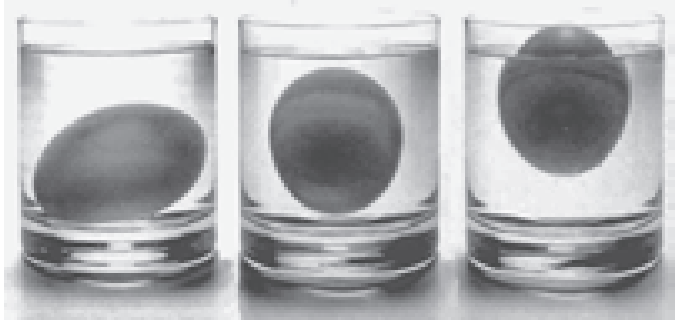

Рис. 5. Чем старше яйцо, тем лучше оно плавает

назад, опускается на дно стакана. Яйцо, которое было снесено неделю назад, плавает в воде в вертикальном положении. Яйцо, которое было снесено по меньшей мере три недели назад, сразу же всплывет, часть его будет выступать из воды. Дело в том, что по мере старения яйца в нем происходят процессы разложения белка и желтка. Эти процессы сопровождаются выделением сероводорода, который частично улетучивается из яйца через мельчайшие поры в скорлупе, частично заполняет имеющуюся в яйце воздушную полость. Поэтому плотность яйца уменьшается.

Но ведь не придешь же в магазин с кастрюлей воды, чтобы проверять свежие яйца или нет?! Можно поступить проще: посмотреть яйцо «на просвет»: если оно просвечивает - значит, свежее, если оно темное - значит, несвежее. Сероводород, выделяющийся в испорченном яйце, уменьшает его прозрачность. В прежние времена в магазинах даже стояли специальные аппараты - овоскопы, в которых имелись ячейки для размещения проверяемых яиц и включалась лампочка, позволявшая увидеть все испытуемые яйца на просвет.

...В заключение попробуйте проделать следующий опыт-фокус. Возьмите две рюмки-подставки для яиц и придвиньте их вплотную друг к другу. В одну из них поставьте сваренное вкрутую яйцо. Сильно подуйте в зазор между яйцом и стенкой рюмки. Яйцо выпрыгнет из рюмки и перепрыгнет в соседнюю. Если фокус получится, постарайтесь его объяснить. 